\title{
Interlinking Personality and Language Learning Strategies
}

\author{
Juanito P. Tandoc JR. ${ }^{1}$ \\ ${ }^{1}$ Faculty of the Department Of Languages and Literature, Isabela State University Echague Campus, Philippines \\ Correspondence: Juanito P. Tandoc JR., Faculty of the Department of Languages and Literature, Isabela State \\ University Echague Campus, Philippines. E-mail: jongt28@gmail.com
}

Received: September 2, 2019 Accepted: November 27, 2019 Online Published: December 28, 2019

doi:10.5539/ijel.v10n1p209 URL: https://doi.org/10.5539/ijel.v10n1p209

\begin{abstract}
The role of personality to language learning has been the subject of research studies in the last years. In line with this, this study aims to determine the predominant personality traits, preferred language learning strategies of $\mathrm{AB}$ English and BSE English students, and the correlation between their predominant personality traits and preferred language learning strategies. Using the concurrent triangulation design, results revealed that the learners' major traits are communicativeness, independence, originality, and conscientiousness traits. They also preferred metacognitive, social, memory and cognitive language learning strategies. It was also revealed that communicativeness is highly correlated with metacognitive, social, and cognitive language learning strategies; independence with memory and cognitive; originality with metacognitive, social and cognitive; and conscientiousness with metacognitive language learning strategies.
\end{abstract}

Keywords: metacognitive, communicativeness, independence, concurrent-triangulation design, psycholinguistics

\section{Introduction}

As the field of second language learning has been developing over the past few decades, second language (L2) research in education has largely focused on learner-centered approaches to second language teaching. In line to this trend of interest, how learning strategies effect the success of language learners has been the main concern of the researchers. Rubin (1975) states that the fundamental assumption behind learning strategies research in second/foreign language education has been that one of the factors that makes learners good is their use of learning strategies.

Language learning strategies (LLS) as a determinant aspect in learning a new language have been defined in different ways. A recent definition is given by Molaei (2002) and stressed that strategies are specific methods of going about a problem or task, modes of operation for attaining a particular end or planned designs for controlling and handling certain information. In this study, the definition of LLS is adopted from Oxford (1990) as specific actions taken by the learner to make learning easier, faster, more enjoyable, more self-directed, more effective, and more transferable to new situations.

Various factors that influence the learning process such as motivation, attitudes, anxiety, learning achievements, aptitudes, intelligence, age, personalities, etc. also played another major area of second/foreign language learning research (Gardner, 1960). The emphasis on the individual differences among learners is important in modern language teaching and its associated learning environments because of these learner variables (Blair, 1982). The success of second language learning is due not only to cognitive factors but also to affective, motivational, personality, and demographic factors of the learners (Brown, 2000; Carrel et al., 1996), among which personality is of great importance (Carrell et al., 1996).

The Manchester Personality Questionnaire Manual (1996) defines the term personality as a distinctive personal character. In language, people use traits to describe personality characteristics: people are described as, for example, creative, conscientious, talkative etc. These trait adjectives describe the way people think, feel and relate with each other. There is a huge variety of personality characteristics in the English language and in the study of personality researchers have endeavored to identify a common core structure of personality based on cluster of traits.

Although personality and learning strategies and many other concepts related to learning have been investigated in numerous studies, there were few numbers of published studies employing mixed method approach exploring 
personality traits of English language learners, cross referencing it with their language learning strategies. Moreover, corroborating a qualitative data gathered, analyzed and interpreted with a quantitative data gathered using a standardized personality questionnaire, specifically using the Manchester Personality Questionnaire Version 14 (MPQ), and language learning strategies tool have not been explored. Hence, this study aims to answer the following research questions:

1) What are the predominant personality traits of the English language learners?

2) What are the most preferred language learning strategies by the English language learners?

3) What relationship exists between the predominant traits and preferred LLS of English Language Learners?

The role of learners' personality is vital in shaping and influencing their behavior in learning a second language or a foreign language. This was already proven by several research (Dewaele, 2013; Öz, 2014a; Dewaele \& Al-Saraj, 2015; Pour, 2016). Since these personality traits are often not seen and unconsciously kept by learners, teachers in classrooms are not aware of the learning behavior of each student, or even care about these individual differences. It is imperative that teachers should be aware of the types of personality traits their students have, since a student's choice of learning strategy and eventually his command of the language is substantially influenced by his personality traits (Zachariah et al., 2011). This paper will therefore provide an insight on the personality traits and language learning strategies employed by both AB English and BSE English language learners because the more the teachers know their students' traits, the more they can effectively guide them in their L2 learning. Without adequate knowledge about their individual students' personality preferences, teachers cannot systematically provide the needed instructional variety (Molaei, 2002).

\section{Materials and Methods}

\subsection{Design}

The study employed mixed method specifically concurrent triangulation design. Concurrent triangulation design employs the gathering of qualitative data and quantitative data. It is selected as the design when a researcher uses two different methods in an attempt to confirm, cross validate, or corroborate findings within a single study (Creswell et al., 2003). Concurrent triangulation design uses separate qualitative method and quantitative method as means to offset the weaknesses inherent within one method with the strengths of the other method.

\subsection{Participants of the Study}

The respondents of this study were the fourth-year students enrolled in Bachelor of Arts in English (AB-English) and Bachelor of Secondary Education major in English (BSE-English) from the two largest campuses of Isabela State University, Isabela, Philippines. As for the qualitative part, 8 participants were involved, 4 students from each program were purposely selected. These were the chosen participants because of their perceived exposure to the different language learning strategies already and not to mention also is their maturity to make decisions for themselves which may elicit more accurate data in gathering the variable of personality traits. Thus, total population was considered in the gathering of the quantitative data while purposive sampling was employed in the gathering of the qualitative data.

\subsection{Instrument}

The instrument used in gathering the quantitative data for personality traits was the standardized test Manchester Personality Traits Questionnaire Version 14 (MPQ) and for the English learning strategies, the Strategies Inventory of Language Learning (SILL) for Second Language (SL) designed by Rebecca Oxford. The Manchester Personality Questionnaire (MPQ) factor version 14 was a 90-item standardized questionnaire which provides a profile on 14 primary dimensions. Items were short statements which require a response to describe the way the respondents tend to think, feel and act; responses are placed in terms of a rating scale of never; occasionally; fairly often; generally and always. In the SILL, language learning strategies were grouped into six categories for assessment: Memory strategies for storing and retrieving information; Cognitive strategies for understanding and producing the language; Compensation strategies for overcoming limitations in language learning; Metacognitive strategies for planning and monitoring learning; and Affective strategies for controlling emotions, motivation, and Social strategies for cooperating with others in language learning. Responses on each item were placed in terms of a rating scale of never or almost never true of me; usually not true of me; somewhat true of me; usually true of me and always or almost always true of me.

The main tool used during the interview was the interview guide with key questions. The interview questions were developed using A Priori Code. A video recorder was used to record and capture the responses of the respondents during the interview. For the naturalistic observation, classroom observations were conducted. The 
teachers of the respondents were informed first of the observation to be conducted in their classes. Dates for trial and final observation and video recordings were scheduled with the teachers upon the approval of the school administrators.

\subsection{Data Gathering Procedure}

To ensure that ethical considerations were followed, approval of authorities and the respondents and participants themselves were secured. In the administration of the questionnaire, the participants were oriented as to how to answer the tool. They were requested to answer all the items honestly, giving their own perceptions about their personality and language learning strategies employed in learning the English language. Before administering the MPQ, the participants were advised to answer the questionnaire in relation to how they learn the English language so as to elicit accurate data from them.

As for the qualitative data, data were gathered using a combination of naturalistic observation (Gay, 1996) and interview (Fontana \& Frey, 2000). The aim of naturalistic observation is to examine behavior within the normal context for which it occurs (Gay, 1996). The interviews involved individual, face-to-face, and verbal interchange with the participants under study. This combined approach of observing and interviewing allow the researcher to determine and describe the personality traits of English language learners and their language learning strategies.

For the naturalistic observation, classroom observations were conducted. The teachers of the respondents were informed first of the observation to be conducted in their classes. Dates for trial and final observation and video recordings were scheduled with the teachers upon the approval of the school administrators. The classes observed were not pre-determined; proceedings followed the natural flow of how classes were conducted. Observations and video recordings for each were undertaken. These excluded the trial observation. The trial observations and recordings were conducted to allow the students and teachers to get used to the process, thus reducing any "halo effect" during the final observation and recordings.

The result of the interviews and observations were recorded and transcribed accurately and cleansed from "transfer error" through corrective listening (Flick et al., 2004). Although there were key questions identified in the researchers' aide memoir, follow-up questions were raised to further probe into the participants' responses during the interview.

\subsection{Treatment of Data}

The collected quantitative data were analyzed using the SPSS Program, wherein, mean scores and ranking were employed to determine the predominant personality traits and preferred language learning strategies of both $\mathrm{AB}$ English and BSE English learners. Pearson $r$ was also used to find out if there is a significant relationship between their predominant personality traits and preferred language learning strategies.

Likert scale for MPQ questionnaire, was only used for the respondents to indicate how they think, act, and feel in different situations. At the same time, it was used for scoring specific traits of the respondents based on the STEN scale used for MPQ where it consists of above average, average, and above average. As for the SILL, ranking, not the qualitative equivalent, was employed on the gathered data from the SILL questionnaire to determine their most preferred language learning strategies. The qualitative interpretation was only used to indicate the responses of the respondents to the statements given in the questionnaire.

Furthermore, the analysis of the qualitative data involved uncovering of the phenomenon and what it means. The analysis involved recognizing the meanings of the phenomenon to the respondents and its similarities and differences to related literatures. Excerpts were presented as part of the analysis to facilitate the understanding of the meaning of the phenomenon.

The extended texts which were the transcribed result of the interviews and observations were subjected to phenomenological reduction through the construction of a repertory grid or coding. Coding was employed to organize and analyze the overwhelming data collected (Hahn, 2008). The grid was constructed to enable the researcher to observe both cool and warm analyses. The cool analysis consisted of the identification of the significant statements of each respondent. These statements served as basis in the conduct of the warm analysis stage where the data categories were formulated and categorized. Reading and re-reading of the significant statements and the researchers' constant vigilance helped facilitate the surfacing of the essence of the phenomenon. Themes were not derived from the significant statements because the themes were already stated as the 14 personality dimensions found in the MPQ and the six categories of the SILL.

The significant statements that emerged from the central questions asked were subjected to member checking procedure via correspondence technique (Lincoln \& Guba, 1985; Patton, 1990) where each of the study participants was individually approached to verify the consistency of the transcription and interpretation. The 
technique was used by the researcher to assure not only the trustworthiness but also the truthfulness of the data reported.

As intended to be done in the study, the findings of the qualitative data were confirmed, cross validated and corroborated with the results of the quantitative data. This aims to offset the weaknesses inherent within one method with the strengths of the other method (Creswell et al., 2003).

\section{Results}

\subsection{Predominant Personality Traits of the Respondents}

Table 1. Predominant personality traits of the respondents

\begin{tabular}{lllllll}
\hline \multirow{2}{*}{ Personality } & AB-English & & \multicolumn{3}{c}{ BSE-English } \\
\cline { 2 - 7 } & Mean Score & $\begin{array}{l}\text { Descriptive } \\
\text { Equivalent }\end{array}$ & Rank & Mean Score & $\begin{array}{l}\text { Descriptive } \\
\text { Equivalent }\end{array}$ & Rank \\
\hline Originality & 6.71 & Average & 3 & 6.52 & Average & 5 \\
Empathy & 3.67 & Average & 13 & 3.46 & Below Average & 12 \\
Communicativeness & 7.65 & Above Average & 1 & 7.74 & Above Average & 1 \\
Independence & 7.52 & Above Average & 2 & 7.32 & Above Average & 2 \\
Rationality & 3.77 & Average & 12 & 3.32 & Below Average & 13 \\
Conscientiousness & 6.70 & Average & 4 & 6.62 & Average & 3 \\
Perfectionism & 2.89 & Below & 14 & 2.44 & Below Average & 14 \\
\hline
\end{tabular}

The results indicated the predominant personality traits of students. Communicativeness, rated as "Above Average" for both programs, got the highest mean of 7.65 and 7.74, respectively. The MPQ Manual defines this trait as being talkative, emotional, and expressive. High scorers in this expressed their feelings, let people know how they feel about things and share their problems with people.

Based on the results, students were found to be high scorers in Communicativeness. Since the respondents are all majoring in English, they are expected to have high confidence in using the language orally and in written form. This was also evident on the interview in which the participants, from both programs, AB English and BSE English, were very expressive, communicative and open to questions being asked and raised by the researcher. Moreover, when they were asked about their dealings with English speaking people, they mentioned that they are friendly, outspoken and outgoing. They even approached them and conversed with them naturally. Among their unedited responses during the interview which shows communicativeness as their personality are the following:

Participant 3: my social interaction is okay. I share, especially, when it comes to culture. It is how we used to cook, like this then, in our province.

Participant 5: I approach them first, then talk to them and I share things about me, so that in turn, they will share things about them, as my professor said. Sometimes, when I already need help I met them on the hall. I help them, Sir.

This personality trait was further manifested in the naturalistic observation conducted where the students openly expressed their knowledge on the subject matter being discussed by the teacher. When the teacher asked her BSE English students about a certain character in the film they watched, one of them eagerly answered, even without being called by the teacher,

Teacher: ... and then saves the day. What else?

Student 3: Exhibits goodness.

Teacher: Exhibits goodness. O anymore?

Student 4: Supernatural powers hahaha!

Teacher: Possessing

Class: Supernatural powers.

Likewise, in the other BSE class, the students confidently answered every question of the reporter and the teacher. When the reporter asked the class regarding their idea on the poem given, one of the students answered,

Student 8: May I answer, that would it be fair if death separates the couple. Okay. We cannot help because it is a natural law of... as a human, that death comes and you can't help it. Basta nangyayari na lang sa 
isang tao ang kamatayan or death. So, it would be fair. (May I answer, it would be fair if death separates the couple, okay. We cannot stop it because it is the natural law of life, that death comes and you can't help it. Death just happens to a man.)

Independence, as second in rank both for AB English and BSE English students got a mean of 7.52 and 7.32, and a descriptive equivalent of "Above Average" and "Average", respectively. The MPQ manual defines this trait as being independent, self-sufficient and resourceful. High scorers prefer to find out things by themselves, require a lot of personal space and like to solve their own problems. Thus, the AB English students are expected to originate action and invent things because their curriculum shaped them to be research oriented thereby producing new knowledge or research results in the field.

Responses of the participants during the interview corroborates with the result of the quantitative data. The participants from both programs show independence in a number of questions asked by the researcher (e.g., ways of handling pressure, describing themselves while learning English, asking for help in learning English). They often use the term "I" and "my" which strongly indicates that they handle mostly the school activities and requirements themselves; that they tend to work alone and do not prefer to be helped by anybody. Albeit the first result revealed that they possess the communicativeness trait, they also tend to be more independent and needed to be alone in times of doing their assignments, requirements and the like. The participants said:

Participant 3: My way of handling pressure is an effective one because I'm submitting my requirements ahead of the deadline before or three days before sir.

Participant 4: When the requirements were announced ahead of time, I actually do it.

Moreover, independence can be clearly seen during the class observation. When the teacher or reporter asked questions to the class, even though they are not sure with their answers, they smartly answered the questions without asking for help from their classmates. In the activity given by the teacher in the BSE class, even though the teacher left the class, it can be clearly seen on the video that the students worked by themselves and did not ask nor copy from their classmates. One of the unedited responses was:

Student 8: No Ma'am I will answer it. I want to answer it by saying... ahhm in biographical criticism we consider the author's life and facts and experience.

Student 10: If I would answer that question my answer is... for me ahh dun sa mga foreshadow ng mga reader ahh nakikita nila ng maigi ahh there will be advantage in the reader ahhm they are, they are inform when there is the author's life.

(If I would answer that question, I would say that readers have an advantage because they can see well if they are informed of the author's life.)

As for the rest of the personality traits, they were rated "Average". For AB English students, Originality was on rank 3 with a mean of 6.71 . This trait is highly related to their program and is related to Independence, the second predominant personality trait of the students. This personality trait was marked on the interview responses of the students where they revealed that they have their own style and way of dealing with their problems and in their language learning, saying,

Participant 4: I think of things to overcome problems. I make myself better last semester. I innovate myself and think of things that will make me, myself and my performance good. I usually shun away from things that are unnecessary.

This was also evident in the class of the AB English students where they showed that they have the ability to think independently and creatively. The student-reporters show creativity and originality in reporting their topics by using varied strategies and methodologies rather than using one for their classmates to easily understand the topic. Similarly, the students answered the questions of the reporters either by giving situational examples or personal experiences deviating from the usual practices of just giving synonymous words and terms to describe what they meant. Thus, originality is being shown in the following scenarios lifted from the naturalistic observation conducted:

Scenario 1 (Reporters used PowerPoint, Power Director and lecture notes)

Reporter 1: We will discuss the wedding ceremonies in India (shows pictures).

Reporter 1: ... and this is an actual wedding ceremony (showing a clip).

Reporter 2: Before the wedding... There are several important ceremonies that take place in the days before an Indian wedding. (The reporter showed pictures and video clips) 
For BSE English students, it can be gleaned on the table that Conscientiousness trait was on rank 3 with a mean of 6.62. According to the MPQ manual, high scorers on this personality trait feel a strong sense of duty and responsibility and tend to be somewhat conservative and customary. the participants showed this conscientiousness trait, when they were asked if they follow rules, regulations and norms of the school and society during the interview. Among their responses were:

Participant 1: What is stipulated in the student handbook, I follow them all.

Participant 4: Yes. Yes, I always play by the rules because I think that rules are made for us to follow so we should be abiding the rules or law. I am not a law breaker and so I'm a law-abiding citizen.

Similarly, the students were very careful in answering the questions of their teacher as well as the reporter. They tend to think first, others think critically before expressing their thoughts. These actions were very obvious during the conduct of the naturalistic observation. Among the scenarios showing this trait were:

Teacher: Why do you think Lena is the hero?

Student 2: Ahmm kasi siya yung babae. She is the girl na hindi nirerecognize yung una and then nakita natin yung mga tao sa paligid niya but then later on nakita natin at the last part na siya rin meron din siyang part dun sa pagkakaligtas ng ibang mga tao. (Ahmm it is because she is the girl that was not recognized by the people at first, but then later on they found out that she has a part in saving the people.)

On the other hand, the least ranked personality traits of BSE students were Empathy, Rationality, and Perfectionism with mean scores of 3.46, 3.32, and 2.44, respectively. For AB English students, Rationality, Empathy, and Perfectionism revealed mean scores of 3.77, 3.67, and 2.89, respectively. These results evidently corresponded with the results of the qualitative data. Revealing no signs of empathy, the participants mentioned,

Participant 7: I am handling problems by myself. When I encountered a problem, in English for example, I do research about the solutions or answers to that problem...I want to answer that question by myself so I can learn more.

Participant 8: I don't want people reject my answer, just like that, and I keep it on myself that's why (laughs) I research for answers.

This was further proven in the naturalistic observation conducted where the students do not stop asking questions from the reporter even though she already ignores and jumps to another topic only to avoid the lengthy questions of her classmates. In this case, the students manifest low empathy with the reporter.

Reporter: Ah it came from the various parts of India ahh it is by ahh "Freto Lafrosa de Paz".

Student 4: Ha? What?

Reporter: Okay. It took 22,000 workmates and 22,000 complete trips.

Students: What? Again? What?

Student 4: Paki ulit. (Again?)

Student 5: What 22,000? Ano yun? (What is that?)

Likewise, the responses of the participants during the interview reflected that they are impulsive and unwary which resulted to undesirable outcomes and which showed that they are really low scorers in Rationality personality trait.

Participant 5: ... there are times that I don't do my best (laughs), yes, I got frustrated. I got frustrated when the time I don't prepare well especially when it is to be prepared today and I don't have a background of anything, I easily got frustrated on the things that I've done.

This being more intuitive and spontaneous of both learners, AB English and BSE English, were mirrored during the naturalistic observation conducted where the students just keep on reporting their assigned topic without even carefully reviewing the subject matter, not even considering the correct pronunciation of words.

Reporter 1: I will share first the trivia or some interest in us of India. Do you know that India is the birthplace of chaste? (Caste supposedly)

Class: No! Oh really?

Reporter: So, the original word for chaste is the Sanskrit "Chatura Mata" meaning ahh the four, the four members of an army ahh well it's most likely the edifice, chariots, horses and the flute for troubles.

Furthermore, the students were perceived to be low scorers on perfectionism personality trait. Although one 
participant mentioned about "quality work" most of them tend to get frustrated when they receive their final grades, meaning they do not really aim for perfection that they only tend to expect because they think they did their best. They also mentioned "there are times I don't prepare" and "people will give me another chance to make things better than what I did before" which show that they do not aim for excellence and precision. Similarly, during the class observation, it was also perceived that despite the fact that students show originality and creativity during their reports and classes, still, they are less methodical and less detail oriented.

\subsection{Predominant Language Learning Strategies of the Respondents}

Table 2. Predominant language learning strategies of the respondents

\begin{tabular}{lllll}
\hline \multirow{2}{*}{ Language Learning Strategies } & AB-English & \multicolumn{3}{c}{ BSE-English } \\
\cline { 2 - 5 } & Mean Score & Rank & Mean Score & Rank \\
\hline Memory & 3.46 & 3 & 3.41 & 5 \\
Cognitive & 3.45 & 4 & 3.57 & 3 \\
Metacognitive & 3.68 & 1 & 3.74 & 1 \\
Social & 3.67 & 2 & 3.70 & 2 \\
\hline
\end{tabular}

The result presented the predominant language learning strategies of AB English and BSE English students in which Metacognitive was ranked 1 for both programs with mean scores of 3.68 and 3.74, respectively. Likewise, for both courses, Social LLS ranked 2nd with mean scores of 3.67 and 3.70, respectively.

The rest of the results indicated differences in terms of rank between the two programs. For AB English respondents, Memory was on rank 3 with a mean of 3.46, while for BSE English respondents, Cognitive was on rank 3 with a mean of 3.57 .

3.3 Correlation Between the Predominant Personality Traits and Language Learning Strategies Preferred by AB English Learners

Table 3. Correlation between the predominant personality traits and language learning strategies preferred by AB English learners

\begin{tabular}{lllllllll}
\hline & LLS & Memory & \multicolumn{2}{c}{ Cognitive } & Metacognitive & Social \\
\cline { 2 - 9 } Personality & $\mathbf{r}$ & $\mathbf{p}$ & $\mathbf{r}$ & $\mathbf{p}$ & $\mathbf{r}$ & $\mathbf{p}$ & $\mathbf{r}$ & $\mathbf{p}$ \\
\hline Originality & & & & & & & & \\
Communicativeness & 268.89 & 0.22188 & 400.65 & $\mathbf{0 . 0 0 4 1 7 * *}$ & 326.53 & $\mathbf{0 . 0 1 4 4 7 * *}$ & 238.85 & $\mathbf{0 . 0 0 0 2 7 * *}$ \\
Independence & 274.44 & 0.70760 & 420.66 & 0.05567 & 391.82 & $\mathbf{0 . 0 0 1 4 2 * *}$ & 207.84 & 0.20579 \\
\hline
\end{tabular}

Note. *Significant; **Highly Significant; Not Significant (unmarked).

The correlation between personality traits (as measured by personality scale) and language learning strategies (as measured by language learning strategies scale) was investigated using Pearson $r$ as shown in the table. The predominant personality traits and language learning strategies of AB English students were highly considered to answer the third question posed in this study.

Communicativeness, the first in rank personality trait of AB English students, showed a significant relationship with Metacognitive language learning strategy ( $\mathrm{p}$-value $=0.00412$ ), the first in rank among the language learning strategies used by the same students. The rest of the predominant language learning strategies showed a not significant result to Communicativeness.

The second predominant personality, Independence, showed a highly significant relationship with Memory language learning strategy with a p-value of 0.00000 . Since the students also tend to be self-sufficient, mostly require a lot of personal space, like to solve their problems alone, and work best alone, it is also expected that they prefer using their own knowledge in learning the language rather than relying from others. They tend to create their own mental linkages rather than asking questions about what they intend to learn.

It can also be gleaned from the table that the personality of AB English students, Originality, shows a highly significant relationship with Metacognitive and Social language learning strategies with p-values of 0.01447 , and 0.00027 , respectively. However, this personality resulted to a not significant relationship with Memory, the third predominant language learning strategy of AB English students. 
3.4 Correlation Between the Predominant Personality Traits and Language Learning Strategies Preferred by the BSE English Learners

Table 4. Correlation between the predominant personality traits and language learning strategies preferred by the BSE English learners

\begin{tabular}{lllllllll}
\multicolumn{1}{c}{ LLS } & \multicolumn{2}{l}{ Cognitive } & \multicolumn{2}{l}{ Metacognitive } & \multicolumn{2}{l}{ Social } \\
\cline { 2 - 8 } & $\mathbf{r}$ & $\mathbf{p}$ & $\mathbf{r}$ & $\mathbf{p}$ & $\mathbf{r}$ & $\mathbf{p}$ \\
\hline Personality & & & & & & \\
\hline Communicativeness & 166.76 & 0.51257 & 181.45 & 0.07980 & 142.46 & $\mathbf{0 . 0 3 6 6 6 * *}$ \\
Independence & 259.78 & $\mathbf{0 . 0 5 0 5 9 *}$ & 203.59 & 0.57329 & 153.65 & 0.44715 \\
Conscientiousness & 194.63 & 0.51419 & 255.54 & $\mathbf{0 . 0 0 0 2 6 * *}$ & 147.60 & 0.18271 \\
\hline
\end{tabular}

Note. *Significant; **Highly Significant; Not Significant (unmarked).

The correlation between personality (as measured by personality scale) and language learning strategies (as measured by language learning strategies scale) was investigated using Pearson $\mathrm{r}$ as shown in the table. The predominant personality and language learning strategies of BSE English students were highly considered to answer the third question posed in this study.

It was evident that Communicativeness, the 1st predominant personality trait of the BSE English students, has a significant relationship with Social language learning strategy with a p-value of 0.03666 .

The second in rank among the personality traits of students, Independence, revealed a significant relationship with Cognitive language learning strategy with a p-value of 0.05059. BSE English students use Cognitive strategy in language learning and results indicated that there is a connection with their personality trait, Independence.

As for Conscientiousness, it can be perceived from the table that it has a significant relationship with Metacognitive language learning strategy with a p-value of 0.00026 . This significant correlation between Conscientiousness and Metacognitive language learning strategy indicated that since the BSE students feel a strong sense of duty and responsibility and tend to be somewhat conservative and customary, they also have the tendency to carefully arrange and plan their learning and critically evaluate its outcome.

Considering that Conscientiousness trait and Metacognitive learning strategies involved planning, arranging, monitoring, and evaluating their own learning, can be related on how the students work on their academic requirements. Although it was earlier revealed that they are low scorers on Rationality trait which involves carefully and critically analyzing the pros and cons of their actions, they also have the tendency to be cautious in their dealings with other people and diligent in their academic pursuit. Results may show that they do not have a strong rational decision-making skill, but because of their motivation and strong desire to pursue quality work and success in their field of specialization, they thoroughly and conscientiously follow rules to achieve their goals and to compensate their lack of skills in decision making.

\section{Discussion}

The study revealed that both AB English and BSE English students possess similar predominant and least ranked personality traits. These predominant traits were associated with the learners' curriculum and how their professors and the university trained them to be competent and proficient in their fields of specialization. Their subjects, practices, rules and regulations pertaining to the speaking of the English language helped them become holistic individuals. The learners' traits of being communicative, independent, conscientious, and original, reflect that they already possess higher level literacy, communication, and critical thinking, and they already manifest high-level communicative competencies in English, thereby achieving their programs' objectives and outcomes.

Based on the results, both respondents from the AB English and BSE English programs were found to be high scorers in Communicativeness. Since the respondents are all majoring in English, they are expected to have high confidence in using the language orally and in written form. This is also a result of the program objectives of both AB English and BSE in English programs which is to enhance the communicative competence of English majors and to produce graduates who manifest high-level communicative competencies in English and other languages spoken universally and have the basic and higher level literacy, communication, numeracy, critical thinking, learning skills needed for higher learning.

While it is true that their most predominant personality trait is communicativeness, independence still played a big importance in their learning the language as revealed in the data of the study which means that the learners, 
both AB English and BSE English, are also self-contained and prefers to work alone. This means further that they are being communicative and expressive in their dealings with other people but they also desire to be alone to have their own personal space which implies that in class, they tend to be social, outgoing, and prefers to be working in groups, but they also have this trait of being independent and self-governing when it comes to learning. Hence, either group work or working alone, works for them. Furthermore, this trait can also be attributed to the 21 st century learning environment where teachers are using social media platforms, learning management systems, emails and the like in their classes where the students are required to submit or post requirements online. In this so-called internet-era, communication between the teacher and the student can be through emails where face-to-face communication like in a classroom is no longer required. Thus, students do not feel pressured in using the target language orally or verbally anymore. This contributes to the reduction of their apprehension because they are given more time to think and to encode their ideas.

The AB English students are expected to originate action and invent things because their curriculum shaped them to be research oriented thereby producing new knowledge or research results in the field. This is evident in the program outcomes of the $\mathrm{AB}$ English curriculum stating that students should apply and disseminate knowledge in the fields of language, literature, and linguistics through research, linkages, extension, production and networking programs. They are also expected to generate their own teaching styles which can be seen when they were tasked to report in their classes primarily that their curriculum does not entirely focus on pedagogy of the teaching profession. While $\mathrm{AB}$ English are expected to be original, BSE students are expected to be conscientious since they are anticipated to be holding the hardest responsibility of educating the young minds. They have the predisposition of valuing rules so that they can impose it to their students in the near future.

These further revealed that the students tend to feel more comfortable when they are well-prepared and organized. They are very motivated and goal-oriented which make them very determined in their academic efforts and persevering to pursue quality and excellent work. It also implies that these students tend not to be impulsive and they avoid trouble to achieve high levels of success through purposeful planning and persistence. This trait is a reflection of how the BSE English learners were trained by their teachers to be quality driven. It is expected that these student-teachers aim for quality work to produce quality education to their soon- to- be learners. This is also a manifestation of how the institution prepares and develops highly qualified basic education teachers and skilled technologists through quality and well-rounded pre-service training in both academic and vocational fields for diverse communities of learners.

On the contrary, the least ranked personality traits of both learners revealed that they tend to show individualism and self-reliance rather than being supportive, sensitive, and considerate to their classmates' feelings which reflects their sense of independence and self-absorbed rather than being empathetic with others. They tend to work by themselves and never relied on others' help. Although they are communicative, they are still not concerned about others' feelings and they tend to just say whatever they want without necessarily considering the feelings of others. They also tend to take decisions without necessarily establishing the facts and without gathering a lot of information and sometimes fail to predict the consequences of their actions. Even so they mentioned that they plan, study, analyze, evaluate, and even organize the course of their action, still their statements show that they still have the tendency to be impulsive and spontaneous in making decisions and critical actions. The students also tend not to strive for flawlessness and that they tend not to set high performance standards, meaning they are not perfectionist.

These least ranked personality traits of the participants should be developed most importantly because these three (3) correlates to Conscientiousness and Independence (MPQ Technical and User Manual), which were revealed as their predominant personality traits.

Furthermore, findings in the LLS preferences of the students suggest that they can either be independent or social learners which is directly and evidently related to their personality traits. They are using metacognitive learning strategies so they can set their own goals and plan their learning, and afterwards monitor their own progress in learning. They tend to have their own ways of learning the language but they also have the tendencies to socialize and be in groups. Since they prefer metacognitive strategies where it entails reflective thinking, planning, monitoring and evaluating their own learning, it shows that independence is their personality trait. However, independence and using metacognitive strategies do not mean that they do not need other people and they avoid other people's help, more so, that their predominant personality is also communicativeness. This simply means that they effectively learn when they are alone, but they also value their relationship with their peers so they are open in learning with others. They recognize and value other people's help and contribution to their language learning but are still not dependent on others. 
Likewise, their use of memory and cognitive language learning strategies showed that still, these learners memorize, associate, review, and analyze their lessons privately or in groups. Hence, teachers may give activities and exercises to enhance the memory and cognitive abilities of the learners.

Correlation results implied that the personality of the $\mathrm{AB}$ English students was highly correlated to their predominant language learning strategies. This further indicates that students having these personality traits, Communicativeness, Independence and Originality tend to use Metacognitive, Cognitive and Social strategies in their language learning, thereby proving the results indicated in Table 1 and Table 2 . These were also observed during the interview and naturalistic observation conducted where the participants revealed that these language learning strategies best helped them in their language learning. It also indicated that the predominant personality traits have direct relationship with the most preferred language learning strategy of both learners, AB English and BSE English. These students are characterized by a unique pattern of traits, and these language learning strategies which resulted to significant relationships best suit their qualities. It is expected that Communicativeness, which is defined as being communicative, open and expressive of one's inner thoughts and feelings have a direct relationship with social language learning strategy. When a person's personality is open and expressive, he/she may likewise feel comfortably learning with the help of others, or when they are in groups.

\section{Conclusion}

This research study found out that the personality traits of the participants proved that learners in general have more than one trait and the differences are in terms of the degree of those personality constructs. It also discovered that they employ various strategies in learning a language. With these results of the study, it is therefore imperious to conclude that the need to determine students' personality traits and language learning strategies as basis for delivering receptive and responsive instruction has never been more vital than it already is. The instruction that is receptive and responsive to students' different traits and learning strategies is essentially critical as the number of students who enroll in AB English and BSE English programs has become progressively more diverse.

As for its pedagogical implication, sometimes looking at an instruction from a viewpoint of the learner rather than a teacher is advantageous, since it puts into correct perspective the widely accepted view that if instruction is based on accurate content and which employs effective teaching strategies, then learning is facilitated. And so, teachers in order to be more effective in delivering quality instruction to the learners, they need to think like the learners, feel them, understand them and most importantly value them for they are the ones providing the hint or indication as to how they wanted and what they wanted to learn.

The results of the study also revealed that the language teaching strategies of teachers may affect the personality and preferred language learning strategies of learners, delving into the relationship of these teaching strategies to learners' personality and learning strategies may be considered for future studies. It is also important to find out the personality traits and language learning strategies of the learners at the start of the course to help teachers employ the teaching strategy best suited for these types of learners.

Furthermore, results show that there are predominant and least ranked traits and language learning strategies. Teachers may consider giving learning activities or enhancement exercises to help learners be adept on the use of varied strategies in English language learning. They may also devise exercises or drills that would help learners develop their least ranked but important traits while enhancing their predominant ones, hence, embedding these 2 important aspects in the course or curricula of the students may be considered. Additionally, since a high percent of learners' knowledge comes from the teacher, it is recommended that they may be sent to trainings to update and upgrade their knowledge on the current trends and issues on personality and language learning strategies so they can provide these latest trends in their language teaching.

\section{References}

Al-Buainain, H. (2010). Language learning strategies employed by English majors at Qatar university: Questions and queries. Asiatic, 4(2).

Blair, R. W. (1982). Innovative approaches in language teaching. Rowley, MA: Newbury House.

Brown, H. D. (2000). Principles of language learning and teaching (4th ed.). White Plains, NY: Longman.

Carrel, P. L., Prince, M. S., \& Astica, G. G. (1996). Personality type and language learning in an EFL context. Language Learning Journal, 46(1), 75-99. https://doi.org/10.1111/j.1467-1770.1996.tb00641.x

Clement, R. (1980). Ethnicity, contact, and communicative competence in a second language. In H. M. Giles, W. 
P. Robinson \& P. M. Smith (Eds.), Language: Social Psychological Perspectives. Pergamon: Oxford.

Dewaele, J.-M. (2013). Emotions in multiple languages (2nd ed.). Basingstoke: Palgrave Macmillan.

Dewaele, J.-M., Petrides, K. V., \& Furnham, A. (2008). The effects of trait emotional intelligence and sociobiographical variables on communicative anxiety and foreign language anxiety among adult multilinguals: A review and empirical investigation. Language Learning, 58(4), 911-960. https://doi.org/10.1111/j.1467-9922.2008.00482.x

Dewaele, J.-M., \& Thirtle, H. (2015). Why do some young learners drop foreign languages? A focus on learner-internal variables. International Journal of Bilingual Education and Bilingualism, 12(6), 635-649. https://doi.org/10.1080/13670050802549656

Dollman, L., Morgan, C., Pergler, J., Russell, W., \& Watts, J. (2007). Improving social skills through the use of cooperative learning (pp. 1-82). Eric Digest, ED496112.

Dörnyei, Z. (1994). Motivation and motivating in the foreign language classroom. The Modern Language Journal, 78(3), 273-284. https://doi.org/10.1111/j.1540-4781.1994.tb02042.x

Dörnyei, Z. (2005). The psychology of the language learner: Individual differences in second language acquisition. London, England: Erlbaum.

Dörnyei, Z., \& Murphey, T. (2003). Group dynamics in the language classroom. Cambridge, England: Cambridge University Press. https://doi.org/10.1017/CBO9780511667138

Fontana, A., \& Frey, J. H. (2000). The interview: From structured questions to negotiated text. In N. K. Denzin, \& Y. S. Lincoln (Eds.), Handbook of qualitative research (2nd ed., pp. 645-672). Thousand Oaks, CA: Sage.

Gardner, R. C. (1985). Social psychology and second language learning. London: Edward Arnold.

Gay, L. R. (1996). Educational research: Competencies for analysis and application. New Jersey: Merrill.

Hymes, D. H. (1972). On Communicative Competence. In J. B. Pride \& J. Holmes (Eds.), Sociolinguistics. Selected Readings (pp. 269-293). Harmondsworth: Penguin.

MacIntyre, P. D., \& Charos, C. (1996). Personality, attitudes, and affect as predictors of second language communication. Journal of Language and Social Psychology, 15(1), 3-24. https://doi.org/10.1177/0261927X960151001

MacIntyre, P. D., Dörnyei, Z., Clément, R., \& Noels, K. (1998). Conceptualizing willingness to communicate in a L2: A situational model of L2 confidence and affiliation. The Modern Language Journal, 82(4), 545-562. https://doi.org/10.1111/j.1540-4781.1998.tb05543.x

Molaei, A. (2002). The impact of conscientiousness personality trait on language learning strategy application in EFL context. European Online Journal of Natural and Social Sciences, 2(2), 668-673.

Oxford, R. (1990). Language learning strategies: What every teacher should know? University of Alabama. Boston. Heinle \& Heinle publications.

Pour, F. J. (2016). Metacognitive awareness and attitudes toward foreign language learning in the EFL context of Turkey. Procedia - Social and Behavioral Sciences, 232(1), 459-470. https://doi.org/10.1016/j.sbspro.2016.10.063

Rubin, J. (1975). What the "good language learner" can teach us? TESOL Quarterly, 9(1), 41-51. https://doi.org/10.2307/3586011

Savignon, S. J. (1972). Communicative competence: An experiment in foreign language teaching. Philadelphia, PA: The Center for Curriculum Development.

Tolinson, C. (1999). The differentiated classroom: Responding to the needs of all learners. Alexandria, VA: Association for Supervision and Curriculum Development.

Zachariah, M., \& Olugbile, O. (2011). The relationship between creativity and mental disorder in an African setting. Mens Sana Monographs, 9(1), 225-237. https://doi.org/10.4103/0973-1229.77439

\section{Copyrights}

Copyright for this article is retained by the author, with first publication rights granted to the journal.

This is an open-access article distributed under the terms and conditions of the Creative Commons Attribution license (http://creativecommons.org/licenses/by/4.0/). 